Palavras chave: estação normal de perigo de incêndios estatística de incêndios prevenção

Histórico: Recebido 15/02/2013 Aceito 04/02/2015

Keyworks: Fire season forest fire statistics prevention

Correspondence: tetto@ufpr.br
Alexandre França Tetto'; Ronaldo Viana Soares'; Antonio Carlos Batista'; William Thomaz Wendling'

\section{INCÊNDIOS FLORESTAIS ATENDIDOS PELA KLABIN DO PARANÁ NO PERÍODO DE 1965 A 2009}

RESUMO: O registro de ocorrência dos incêndios florestais possibilita o planejamento de atividades de prevenção e combate, minimizando os danos. Os objetivos deste trabalho foram: determinar o número de incêndios atendidos pelas brigadas de incêndios da Klabin, no período de 1965 a 2009; determinar a distribuição temporal dos incêndios; identificar as causas prováveis; e identificar as principais classes de locais afetados. Para isso, foram analisados os registros de ocorrência de incêndios fornecidos pela Klabin, bem como dados meteorológicos do IAPAR para o período analisado. Os resultados permitiram concluir que, no período de 1965 a 2009, foram registrados 2.3 I 3 incêndios que atingiram 6.197 ha, com redução da área afetada ao longo do período. Os meses de julho, agosto e setembro apresentaram o maior número de ocorrências, totalizando I.I83 (5I,2\%) incêndios. As ocorrências estão distribuídas ao longo da semana de forma homogênea, concentradas ao longo do dia das II às 18 horas (72,8\% do total). As principais causas dos incêndios foram incendiários $(54,2 \%)$ e queimas para limpeza (I6,2\%). A vegetação mais suscetível foi o pinus, com $41,3 \%$ das ocorrências e $22,5 \%$ da área afetada. Apesar de um grande número de ocorrências no eucalipto $(22,2 \%)$, a área atingida foi menor que a de "outras espécies plantadas" (20,4\%) e da capoeira (19,3\%). Conclui-se que houve uma melhoria do sistema de proteção, considerando o aumento da área protegida e a diminuição da área afetada pelos incêndios. Ações de prevenção direcionadas aos incendiários e queimas para limpeza, sobretudo nos períodos de maior perigo, são necessárias.

\section{FOREST FIRES SUPRESSED BY KLABIN OF PARANA IN THE PERIOD 1965 - 2009}

ABSTRACT: The records of fire occurrence enables planning for prevention and control, minimizing the damages. The objectives of this study were: determine the number of fires attended by fire brigades of Klabin in the period of 1965 to 2009, determine the fires temporal distribution, identify the probable causes, and identify the main classes of affected vegetation. To do so, records of fire occurrence provided by Klabin, as well as IAPAR meteorological data for the period were analyzed. The results showed that in the period of 1965 to 2009 , there were 2,313 occurrences that affected 6,197 ha, with a reduction of the affected area over the period. The months of July, August and September presented the highest number of occurrence, totaling I, I83 (5I.2\%) fires. The events were uniformly distributed throughout the week, concentrated from II to I 8 hours (72.8\% of total). The main causes of fires were arson (54.2\%), followed by cleaning burns (16.2\%). The pine was the more susceptible vegetation, with $41.3 \%$ of the occurrences and $22.5 \%$ of the affected area. Although a large number of events occurred in eucalyptus (22.2\%), the affected area was smaller than that "other planted species" $(20.4 \%)$ and secondary forest (19.3\%). In conclusion, there was an improvement of the protection system, considering the increase of the protected area and the decrease in the area affected by fires. Preventive actions directed to arsonists and agricultural burning, especially in periods of danger are needed. 


\section{INTRODUÇÃO}

A redução da cobertura vegetal e o aumento das atividades antrópicas, ao longo do tempo, resultaram em um aumento no risco de incêndios florestais. Esses eventos estão presentes no planeta desde os tempos mais remotos (RODRIGUEZ; SOARES, 2004) e têm causado sérios danos ambientais, sociais e econômicos, sendo que suas ocorrências dependem, entre outros aspectos, da época do ano e da sua localização geográfica. Em muitos países esta situação tem se intensificado em virtude do aumento populacional, acúmulo de material combustível e atividades antrópicas (SOARES, 2009). Somados a estes aspectos, a mudança espaço-temporal do clima altera o regime do fogo, ou seja, os padrões, a frequência e a intensidade dos incêndios, além da sua distribuição (KRAWCHUK et al., 2009).

Apesar da adoção de práticas protecionistas, a cada ano, o fogo destrói ou danifica grandes extensões florestais no mundo (SOARES; BATISTA, 2007). De acordo com Soares (2009), para o estabelecimento de uma política adequada de prevenção de incêndios é necessário conhecer as estatísticas referentes aos mesmos. A falta dessas informações pode levar a um dos seguintes extremos: gastos acima do potencial de danos ou gastos pequenos, colocando em risco a sobrevivência da floresta, bem como de todo ecossistema associado.

De acordo com Heikkilä et al. (2007), a primeira etapa de um plano de prevenção contra os incêndios florestais é a coleta de informações básicas sobre a ocorrência de incêndios pelo menos dos últimos cinco anos, respondendo as seguintes questões: como ou porque os incêndios começaram, quando eles iniciaram e quando eles ocorrem mais frequentemente.

De acordo com Soares (1992, 2009), apesar da importância desses dados para ações de prevenção e combate aos incêndios florestais, não existe o registro atualizado de ocorrência de incêndios que permita conhecer o perfil dos incêndios florestais no Brasil. Somente algumas empresas florestais têm mantido registro confiável das ocorrências ao longo dos anos.

Para a tomada de decisões, relacionadas à prevenção e ao combate em áreas a serem protegidas, é importante que se tenha o Registro de Ocorrência de Incêndio (ROI), devendo conter, no mínimo, as seguintes informações: data de ocorrência, extensão da área queimada, causa, local de ocorrência e tipo de vegetação atingida. $\mathrm{O}$ ROI deve ser realizado logo após o combate e pode também conter informações sobre: deslocamento, combate e controle do fogo, recursos humanos, equipamentos e produtos utilizados, pontos positivos e negativos observados no combate (TETTO et al., 20I I).

De acordo com Dias (2010), a origem do incêndio florestal está relacionada ao analfabetismo ambiental (desconhecimento do indivíduo das consequências de seus atos), à ocorrência de um incidente (fogueiras mal apagadas, rompimento de cabos de alta tensão, fagulhamento de veículos pesados, entre outros), aos aspectos culturais (rituais religiosos, conflitos rurais, balões de festa junina, piromania, entre outros), aos fenômenos naturais (raios), ao extrativismo (caça, pesca, retirada de madeira, coleta de frutos, entre outros) e à política agrária (pela falta de estímulo às formas de produção que não utilizem as queimadas). $O$ conhecimento das principais causas dos incêndios é importante para se realizar um trabalho objetivo de prevenção, visando à redução daquelas causas mais frequentes (SOARES; BATISTA, 2007). As principais causas dos incêndios florestais podem mudar não apenas regionalmente, sobretudo em países de grande extensão territorial, mas também ao longo do tempo (SOARES, 1992).

De acordo com Soares (2009), é necessário saber quando os incêndios ocorrem para se estruturar os serviços de prevenção e combate dentro de limites economicamente viáveis, ativando o sistema durante os períodos críticos e desativando-o parcialmente nos de menor risco. Para Batista (1990), a distribuição mensal de ocorrência de incêndios determina a estação normal de perigo de incêndios, que varia de uma região para outra, sendo dependente da quantidade e distribuição da precipitação pluviométrica e do efeito desta sobre a vegetação. Da mesma forma, os incêndios não ocorrem de maneira uniforme em uma determinada área ou região. Segundo Chas-Amil et al. (20l0), é crucial para a aplicação de políticas de prevenção de incêndios conhecer o padrão espacial de ocorrência e suas relações com os aspectos geográficos e econômicos.

Além dessas informações, é importante o conhecimento da área queimada, que reflete, entre outras variáveis relacionadas ao comportamento do fogo, a eficiência do sistema de proteção. Quanto mais rápidas forem a detecção e o deslocamento, aliados a um combate eficiente, menor serão os danos causados pelo 
fogo (TETTO et al., 20I I). O tipo de vegetação é outro dado importante, pois possibilita analisar quais os tipos de vegetação mais suscetíveis ao fogo em determinado local, estando relacionado também à sua combustibilidade e inflamabilidade (BATISTA, 1990).

Tendo em vista os impactos causados pela ocorrência de incêndios florestais, a importância do registro de suas ocorrências, a escassez de dados históricos de forma organizada e confiável, o objetivo deste trabalho foi traçar um perfil dos incêndios florestais atendidos pelos brigadistas da Klabin durante 45 anos, de 1965 a 2009. Para isto foi necessário desenvolver os seguintes objetivos específicos: a) determinar o número de incêndios registrados e as respectivas áreas queimadas; b) identificar as causas prováveis, de acordo com os relatórios dos incêndios; c)determinar a distribuição dos incêndios através dos meses do ano, dos dias da semana e das horas do dia; d) determinar a vegetação mais suscetível aos incêndios.

\section{MATERIAL E MÉTODOS}

\section{Caracterização da área}

A presente pesquisa foi desenvolvida na área atendida pela equipe de brigadistas da empresa Klabin Paraná, situada predominantemente no município de Telêmaco Borba, PR, no segundo planalto da região centro-paranaense, com relevo suavemente ondulado, entre as coordenadas $24^{\circ} 03^{\prime}$ e $24^{\circ} 28^{\prime}$ de latitude sul e $50^{\circ} 2 I^{\prime}$ e $50^{\circ} 43^{\prime}$ de longitude oeste (SOARES, 1972; NUNES et al., 2009; NUNES et al., 2010). A área inicialmente atendida era de 143.61 I, 16 ha, em 1965, passando atualmente para 274.934, 16 ha de área própria e de terceiros, correspondendo a um aumento de 9 I,4\% no período analisado.

A precipitação anual média da região é de $1.490 \mathrm{~mm}$, distribuído em todos os meses do ano, com excedente hídrico de $557 \mathrm{~mm}$.ano-1, a temperatura média anual é de $19^{\circ} \mathrm{C}$ e a umidade relativa média do ar 76,5\%. De acordo com a classificação de Köppen o clima da região pertence ao tipo $\mathrm{Cfb}$, ou seja, temperado úmido, sem estação seca, com verão fresco e geadas periódicas. Segundo a classificação de zonas de vida de Holdridge, a região está localizada na formação ecológica bosque úmido temperado (MAACK, 1968; SOARES, 1972; NUNES et al., 2010). Nunes et al. (2009), analisando dados de precipitação mensal e número de dias de chuva no período de 1947 a 2005, concluiu que: os meses mais chuvosos são dezembro, janeiro e fevereiro; e os menos chuvosos são julho e agosto.

\section{Obtenção e análise dos dados}

Os registros dos incêndios atendidos, desde 1965, estavam em um banco de dados, do qual foram utilizadas as seguintes informações: data, área queimada, hora de detecção do fogo, causa provável e tipo de vegetação atingida. Esses dados foram tabulados, padronizados e analisados a fim de proporcionar a maior quantidade possível de informações sobre a ocorrência de incêndios. Além das estatísticas fundamentais do número de incêndios e respectivas áreas queimadas, foram analisadas a distribuição através dos meses do ano, das horas do dia e dos dias da semana, a identificação da causa provável e a separação em tipos de vegetação atingidos. Foram também analisados dados históricos de precipitação e umidade relativa, no período de 1976 a 2009, da estação meteorológica do Instituto Agronômico do Paraná (IAPAR), situada em Telêmaco Borba.

Os dados das ocorrências e respectivas áreas queimadas foram tabulados de acordo com os meses do ano para se identificar a estação normal de perigo de incêndios; de acordo com as horas do dia, para se verificar quando eles iniciaram; e de acordo com os dias da semana, para se testar a hipótese de que as ocorrências se distribuem uniformemente através deles. Os tipos de vegetação foram agrupados em sete classes: pinus, eucalipto, campo, capoeira, floresta, outras espécies plantadas e agricultura, para se verificar a suscetibilidade dessas áreas à ocorrência do fogo.

A classificação desenvolvida pelo Serviço Florestal dos Estados Unidos e adotada nas publicações da Food and Agricultural Organization (FAO) foi utilizada com o intuito de padronizar e analisar as causas dos incêndios florestais (SOARES, I97I; BROWN; DAVIS, 1973; SOARES, 1979; BATISTA, 1990; SOARES; BATISTA, 2007; HEIKKILÄ et al., 2007), que englobam oito grupos, a saber: raios, incendiários, queimas para limpeza, fumantes, operações florestais, fogos de recreação, estradas de ferro e diversos.

\section{RESULTADOS E DISCUSSÃO}

Foram registrados, no período de 1965 a 2009 , 2.313 ocorrências de incêndios florestais atendidas pela equipe de brigadistas da Klabin. A média anual foi de 5I,4 
ocorrências, com aumento no número de atendimentos, em virtude da ampliação da área sob a responsabilidade da Empresa. Na Figura I, observam-se os anos com número de ocorrências abaixo da média (em branco) e, acima da média (em preto), bem como a linha de tendência dada pela equação polinomial apresentada. Os anos de 1994, 1999, 2000 (VOSGERAU et al., 2006) e 2007 (TETTO et al., 2012) também foram identificados como acima da média de ocorrência de incêndios por outros pesquisadores.

Apesar do aumento do número de ocorrências observado na Figura I, houve uma redução na área afetada pelos incêndios florestais nesse mesmo período. Isto, de acordo com Soares (2009), se deve possivelmente "ao maior cuidado que as empresas
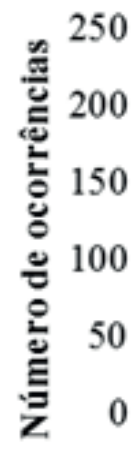

florestais têm dedicado ao problema do fogo, tanto através de campanhas educativas para prevenir os incêndios como na melhoria da infraestrutura de controle, para combatê-los quando ainda estejam pequenos e com baixa a média intensidade".

Foram registrados 6.197 ha atingidos por incêndios florestais, uma média de 137,7 ha por ano. Ainda, em termos de área atingida, destaque deve ser dado para o ano de 1967, com a ocorrência de cinco incêndios, que atingiram I.300 ha (21\% da área atingida no período analisado). Na Figura 2, os anos com área afetada abaixo da média encontram-se em branco e, acima da média em preto, sendo também apresentada a linha de tendência dada pela equação polinomial.

Uma maior ocorrência de incêndios foi observada nos meses de julho, agosto e setembro,

$$
\begin{gathered}
y=0,1118 x^{2}-2,6189 x+33,665 \\
R^{2}=0,6127
\end{gathered}
$$

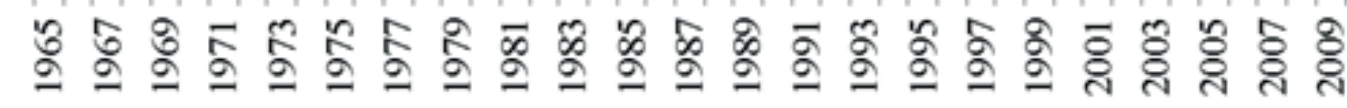

\section{Periodo (anos)}

FIGURA 1 Número de ocorrências de incêndios no período analisado.

FIGURE 1 Forest fire occurrences in the analyzed period.

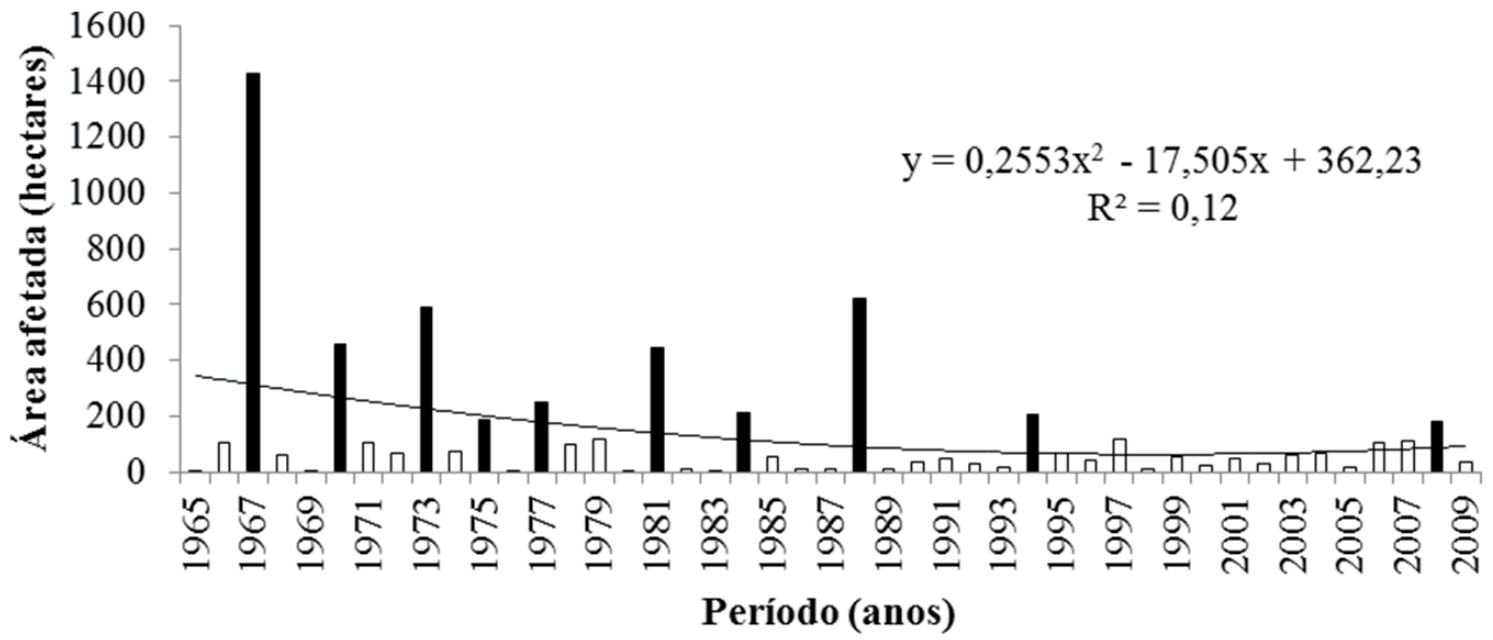

FIGURA 2 Área atingida por incêndios Florestais no período de 1965 a 2009.

FIGURE 2 Affected area by forest fires in the period 1965 to 2009. 
que coincide com o período de menor precipitação pluviométrica (Figura 3). Esses meses totalizaram I. 183 ocorrências de incêndios, no período analisado, o que correspondeu a $5 \mathrm{I}, 2 \%$ do total. Muito semelhante ao resultado encontrado por Tetto et al. (2012) para o qual o período normal de ocorrência de incêndios se concentrou nos meses de junho a setembro, com $52,5 \%$ dos registros.

Observa-se ainda que, de acordo com Vosgerau et al. (2006), os incêndios florestais se concentram no final do inverno e início da primavera, por apresentar as médias mais baixas de precipitação pluviométrica e umidade relativa do ar. De acordo com a série histórica de dados da estação meteorológica do IAPAR, as médias mais baixas foram nos meses julho e agosto (95,2 e 70,3 $\mathrm{mm}$, respectivamente), os mesmos meses citados por Nunes et al. (2009). A média mensal da umidade relativa foi de $78,9 \%$, no período de 1979 a 2009, com menores índices nos meses de setembro $(76,2 \%)$, outubro $(76,1 \%)$ e novembro $(74,9 \%)$.

Analisando-se as ocorrências em relação aos dias da semana, não foi observada diferença significativa entre os tratamentos, refutando-se a hipótese de que nos finais de semana há maior número de registros de incêndios, muito embora quinta e domingo apresentassem leve acréscimo em relação aos demais dias da semana no período, com 15,4\% e 14,6\% das ocorrências, respectivamente.

Foram registrados os horários de detecção dos incêndios em $97,5 \%$ dos casos sendo, a grande maioria, $72,8 \%$ detectada entre as II e I 8 horas.

Cabe destacar as variações da temperatura e da umidade relativa do ar durante o dia, bem como - maior fluxo de pessoas nesses horários, fatores que influenciam no material combustível e na fonte de propagação, aumentando o risco de incêndio (SOARES; BATISTA, 2007).

As principais causas dos incêndios foram incendiários (54,2\%), seguida por queimas para limpeza ( I6,2\%), não havendo uma variação expressiva das causas em relação aos dias da semana. No que diz respeito às causas em relação ao mês do ano, destaca-se o aumento das causas: "incendiários" e "queima para limpeza" na estação normal de perigo de incêndios, período em que a pouca precipitação, associada a uma baixa umidade relativa do ar e alta temperatura, favorecem o início e propagação dos incêndios florestais. Essas ocorrências, conforme descrevem Vosgerau et al. (2006) e Tetto et al. (20I2) também estão relacionadas com o período de uso do fogo para práticas agrícolas e pastoris.

Das 2.313 ocorrências atendidas, 1.809 atingiram algum tipo de vegetação especificada no registro de ocorrência de incêndios, sendo as demais observadas em infraestrutura (190), resíduos de exploração e material lenhoso (23), margem de rodovia (I0) e sem informação (28I). Com relação à vegetação, a que apresentou maior suscetibilidade à ocorrência dos incêndios foi o pinus (4I,3\%), seguido pelo eucalipto $(22,2 \%)$, campo $(18,2 \%)$ e capoeira (10,3\%). Foram observadas somente $4,3 \%$ das ocorrências em área de floresta, bem abaixo do encontrado por Vosgerau et al. (2006, p. 30), para o estado do Paraná no período de 1991 a 2001 , que foi 31 , II\% das ocorrências. Pode-

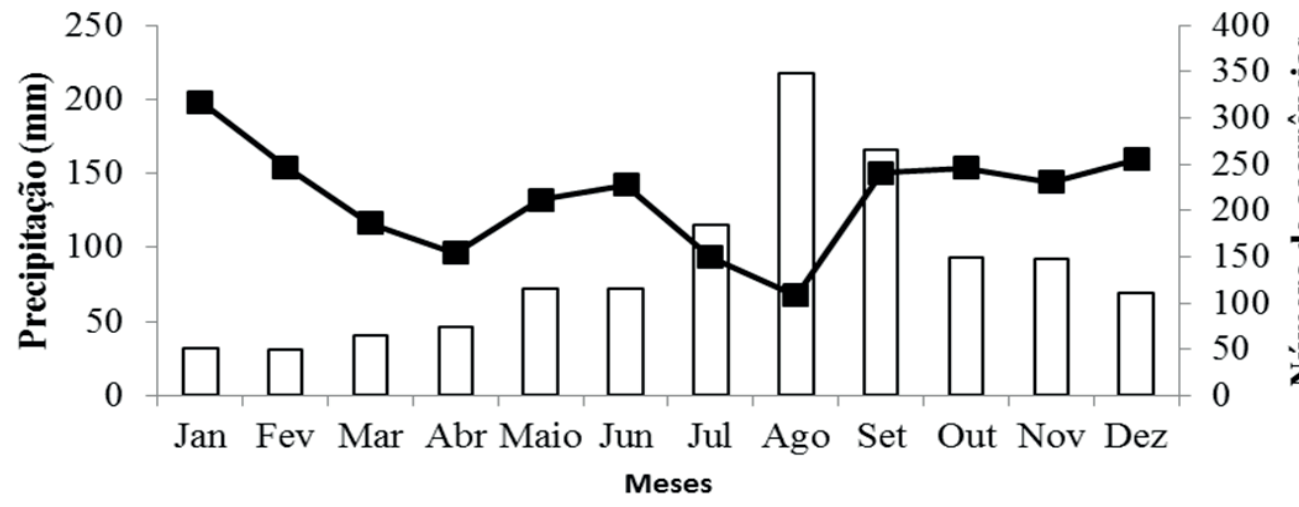

$\square$ Ocorrências $\rightarrow$-Precipitação mensal

FIGURA 3 Número de ocorrências de incêndios e precipitação pluviométrica.

FIGURE 3 Frequency of Forest fires and rainfall. 
se observar que os incêndios nos cultivos de Araucaria angustifolia estão concentrados nos anos iniciais da atividade da Empresa (1965 a 1979), o inverso ocorrendo com o eucalipto, cultura na qual $84,1 \%$ das ocorrências dos incêndios são observadas a partir da década de 90 .

Com relação à área afetada, a maior superfície atingida pelos incêndios foi em cultivo de pinus (22,5\%), seguida por "outras espécies plantadas" (20,4\%) e capoeira (19,3\%). O pinus, por ser a espécie mais plantada e mais inflamável, foi a que apresentou maior número de ocorrências e maior área afetada, o que corrobora com análise feita por Soares (2009). A floresta, apesar de um pequeno número de ocorrências observadas, apresentou 13,6\% do total de área afetada. A relação entre a área atingida e o número de ocorrências mostrou que cada incêndio consome, em média, 15,7 ha de "outras espécies plantadas", 8,4 ha de floresta e 5,0 ha de capoeira, tipos de vegetação que devem receber atenção especial em termos de prevenção e combate.

\section{CONCLUSÕES}

O número de incêndios registrados atendidos pelas brigadas da Klabin foi de 2.3 I3, atingindo uma área de 6. 197 ha. A principal causa dos incêndios foi "incendiários", seguida por queimas para limpeza. A ocorrência de incêndios se concentra nos meses de julho, agosto e setembro, que coincide com o período de menor precipitação pluviométrica. Não houve diferença significativa entre os dias da semana, sendo o horário das II às 18 horas, 0 intervalo com maior ocorrência de incêndios. A vegetação mais suscetível foi o pinus, com 4I,3\% das ocorrências e $22,5 \%$ da área afetada; apesar de um grande número de ocorrências no eucalipto, sua área atingida foi menor que a de "outras espécies plantadas" e da capoeira. Houve uma melhoria do sistema de proteção contra incêndios florestais no período, considerando o aumento da área protegida e a diminuição da área afetada pelos incêndios.

\section{AGRADECIMENTOS}

Os autores agradecem ao Instituto Agronômico do Paraná (IAPAR) pelo fornecimento de informações da estação meteorológica de Telêmaco Borba e as Indústrias Klabin Paraná, por todo apoio a essa pesquisa, em especial aos seguintes técnicos: Cassiano Ricardo Schneider, Carlos Cesar Santos, Áurio de Souza Bueno, Nilton Luis Venturi e Alexandre Camargo Pontes.

\section{REFERÊNCIAS}

BATISTA, A. C. Incêndios Florestais. Recife: Imprensa Universitária da UFRPE, 1990. II5 p.

BROWN, A. A.; DAVIS, K. P. Forest fire: control and use. 2. ed. New York: McGraw Hill, 1973. 686 p.

CHAS-AMIL, M. L.; TOUZA, J.; PRESTEMON, J. P. Spatial distribution of human-caused forest fires in Galicia (NW Spain). WIT Transactions on Ecology and the Environment, v. 137, p. 247 - 258, 2010.

DIAS, G. F. Fogo na vida: elementos para a percepção dos cenários socioambientais gerados pelas queimadas e incêndios florestais e suas contribuições à mudança climática global: subsídios para a educação ambiental. Brasília: Ibama, 2010.80 p.

HEIKKILÄ, T. V.; GRÖNQVIST, R.; JURVÉLIUS, M. Wildland fire management: handbook for trainers. Helsinki: Ministry for Foreign Affairs of Finland, 2007. 248 p.

KRAWCHUK, M. A.; MORITZ, M. A.; PARISIEN, M.; DORN, J. V.; HAYHOE, K. Global pyrogeography: the current and future distribution of wildfire. PloSONE, São Francisco CA, v. 4, n. 4, e5102, 2009.

MAACK, R. Geografia física do estado do Paraná. Curitiba: Banco de Desenvolvimento do Paraná, 1968. 350 p.

NUNES, J. R. S.; BATISTA, A. C.; SOARES, R. V.; FIER, I. S. N. Climatologia do comportamento da precipitação no Distrito Florestal de Monte Alegre. Floresta, Curitiba, v. 39, n. 4, p. 783 - 792, out./dez. 2009.

NUNES, J. R. S.; FIER, I. S. N.; SOARES, R. V.; BATISTA, A. C. Desempenho da Fórmula de Monte Alegre (FMA) e da Fórmula de Monte Alegre Alterada $\left(\mathrm{FMA}^{+}\right)$no Distrito Florestal de Monte Alegre. Floresta, Curitiba, v. 40, n. 2, p. 319 - 326, abr./jun. 2010.

RODRIGUEZ, M. P. R.; SOARES, R. V. Análisis comparativo entre los incêndios forestales en Monte Alegre, Brasil y Pinar del Río, Cuba. Floresta, Curitiba, v. 34, n. 2, maio/ ago. 2004, p. 101 - 107

SOARES, R. V. Proteção florestal. Curitiba: Centro de Pesquisas Florestais, 197I. I80 p.

SOARES, R. V. Determinação de um índice de perigo de incêndio para a região centro-paranaense, Brasil. 1972. 72 f. Dissertação (Mestrado em Ciências) - Centro Tropical de Ensino e Investigação, Turrialba, Costa Rica.

SOARES, R. V. Prevenção e controle de incêndios florestais. Curitiba: FUPEF, 1979. 72 p.

SOARES, R. V. Ocorrência de incêndios em povoamentos florestais. Floresta, Curitiba, v. 22, n. 1/2, p. 39 - 53, 1992. 
SOARES, R. V. Estatísticas dos incêndios florestais no Brasil. In: SOARES, R. V.; BATISTA, A. C.; NUNES, J. R. S. Incêndios Florestais no Brasil: o estado da arte. Curitiba, 2009. p. I - 20.

SOARES, R. V.; BATISTA, A. C. Incêndios Florestais: controle, efeitos e uso do fogo. Curitiba. 2007. 250 p.

TETTO, A. F; BATISTA, A. C.; SOARES, R. V. Prevenção e combate aos incêndios florestais. Curitiba: SENAR-PR, 20II. 75 p.
TETTO, A. F; BATISTA, A. C.; SOARES, R. V. Ocorrência de incêndios florestais no estado do Paraná, no período de 2005 a 2010. Floresta, Curitiba, v. 42, n. 2, p. 391-398, abr./jun. 2012.

VOSGERAU, J. L.; BATISTA, A. C.; SOARES, R. V.; GRODZKI, L. Avaliação dos registros de incêndios florestais do Estado do Paraná no período de I99I a 200I. Floresta, Curitiba, v. 36, n. I, p. 23 - 32, jan./abr. 2006. 